\title{
Correlates of Early Adolescent Peer and Personal Substance Use in Rural Northern Michigan
}

\author{
Paul D. Sarvela' and E. J. McClendon²
}

Received January 25, 1983

Data were collected from 181 middle school students in rural northern Michigan during May 1982. Student responses concerning peer and personal use of alcohol and nicotine were analyzed. The results suggest that peer substance use is highly correlated with personal substance use, and increases significantly with age. Sexual differences were also noted. This article describes the powerful correlates between peer and personal alcohol and nicotine use (i.e., cigarette smoking), and suggests some hypotheses for this phenomenon.

\section{INTRODUCTION}

Peer pressure plays an important part in many youth decisions including the decision to use both licit and illicit substances. Recent television, radio, and print media reports all point to the "peer reference group effect" as a significant factor in adolescent substance use. The early adolescent usually has several friends who are currently using licit and illicit moodmodifying substances; associating with such friends is thought to influence behavior considerably in terms of drug-taking opportunities (e.g., Andrews and Kandel, 1979; Huba and Bentler, 1980; Jessor and Jessor, 1977).

This research was supported in part by a University of Michigan, School of Education research grant.

'Doctoral candidate, The Depariment of Development, Curriculum, and Teaching; Program in Health Education; School of Education; The University of Michigan, Ann Arbor.

${ }^{2}$ Professor, Health Education, School of Education, Department of Health Behavior and Health Education, School of Public Health, The University of Michigan, Ann Arbor. 
Some researchers have argued that peer influence on drug-taking decisions is more influential than parental authority in these matters, while others claim that peers are of equal or less importance in inducing this behavior (Stephens, 1980). One hypothesis suggests that deficient socialization and inadequate parenting are the reasons why peer pressure is more influential than parental authority (Levine and Kozak, 1979). Regardless of the reasons, it is clear that young adults often want to use drugs to be perceived as acting like adults, in other words, to engage in "adult" behaviors. These "adult" behaviors are not confined to substance use, but may also be reflected in the early adolescent decision to engage in other socially disapproved behaviors such as premarital sexual intercourse (Sarvela and McClendon, 1983).

Despite the often assumed influence of peer pressure on substance use, few studies have examined the topic directly; rather, it is usually examined through post hoc analysis of self-reported recall behaviors and mentioned as an additional finding. More importantly, basic research and programs dealing with rural and small town populations are essentially nonexistent; however, there is a great need for research that can be generalized to this population, since it accounts for fully one-third of all Americans. The few studies (e.g., Napier, Carter, and Pratt, 1981; Tolone and Dermott, 1975) aimed at rural groups have emphasized high school or older populations. Few studies have focused on the early developmental stages of this problem, and these have been primarily of a descriptive nature, avoiding the psychosocial etiologic elements. Such issues as the influence of religiosity, peer pressure, and substance use health beliefs and attitudes are not explored. Because of lack of data in this area, the present investigators examined a preadolescent and early adolescent rural/small town population to determine the impact of peer pressure variables on experiences and beliefs relating to use of alcohol and nicotine, two drugs whose potential for further health problems is dramatic.

\section{METHOD}

The survey was conducted in a small town (population approximately $10,000)$ in Michigan's Upper Peninsula. The closest metropolitan area is some 60 miles away and across the state boundary. Traditional rural employment (e.g., farming, mining, and logging) provides the usual occupations of the area, although light industry is also found (chiefly paper mills). The unemployment rate in the county surveyed at the time of the study was $16.0 \%$. The Upper Peninsula's total unemployment rate for the year of 1981 was $13.3 \%$ (Michigan Employment Security Commission, 1982). 
The subjects were grade 6,7 , and 8 students at the local middle school. A total of 181 students were randomly selected, who represented $34.94 \%$ of the population being studied. Although it cannot be argued that these students are representative of rural America's youth, they may well be representative of this area and possibly of the rural northern Midwest.

Total anonymity was emphasized. The students were not permitted to put their names on the questionnaire or answer sheets, which were scored by an optical scanning machine.

The investigators generated 55 questions dealing with drug knowledge, personal drug use, peer drug use, health beliefs and attitudes, general experiences with alcohol, and demographic variables. The instrument was pretested with 496 subjects in grades 6, 7, and 8 of an Upper Peninsula school system to test for readability and to gain a general understanding of drug use trends in the rural early adolescent population. Appropriate changes were made after the pretest, such as the rewording of certain questions, deletion of poor questions, and the addition of items (not included in the earlier survey) considered important after examination of the data provided by the field test.

Personal use was measured in terms of the reported frequency and quantity of use of both alcohol and cigarettes. Frequency of use was measured by asking "How often do you use drug ' $x$ '?" Possible responses were: I never use it; once a year; four or five times a year; four or five times a month; and more than once a week. Quantity of use was measured by the following question "How much do you use 'a given substance' at one time, on the average?" For example, the options provided regarding alcohol were: I don't drink at all; one or two drinks at a sitting; three or four drinks at one time; five or six drinks at one time; and more than six drinks at one time. Peer use was questioned using a similar format. Peer alcohol use was examined by asking "On the average, about how often do your friends drink alcoholic beverages?" The same response possibilities were used for both peer and personal use questions. One additional question was asked concerning peer use: "How many of your friends use 'a given substance'?" The possible responses ranged from none of them to all of them.

The validity and reliability of this measure, as with any instrument, constitute an important aspect of the research design. ${ }^{3}$ In this project, the reliability of the instrument was measured by three methods: (1) test-retest strategies, (2) correlation of peer and personal substance use, and (3) the reported use of bogus drugs to test subject honesty. The validity of the instrument was assessed by content, criterion-related, and construct measures.

${ }^{3}$ This issue was emphasized by the initial reviewers. We appreciate their comments concerning this matter. 
A test-retest reliability strategy was employed by comparing responses of use indicated in the field test of the instrument with responses in the actual study. No significant differences were found between the two surveys.

The correlations between reported peer and personal substance use were quite high; indeed, they are the central focus of the study. Not only do these findings have interesting psychosocial implications but they also point to an instrument that is stable and internally consistent.

The final measure of reliability was built into the instrument, through the use of three lie scale questions. The reported use reliability was above $95 \%$ for these questions.

The issue of instrument validity is whether the instrument actually measures what it purports to. In some types of research (personality, psychoanalytic), this is an extremely difficult matter to establish. However, this study focused on observable behavior, avoiding the psychodynamics of drug use, making instrument validity much less of a challenge.

Kerlinger (1973) argues that content validity refers to whether or not the instrument is representative of the content of the property being measured. In this case, the content validity of the instrument is self-evident. For example, a question measuring the frequency of alcohol use does so objectively, using well defined Likert-type responses. No inferences are drawn beyond those revealed in the actual responses.

Criterion-related validity is addressed through the correlates between peer and personal substance use. Here the issue is "how solid a predictor is the instrument?" (Kerlinger, 1973). The correlates (described in the Results section) indicate a strong correlation, indicating that criterion-related validity is substantial.

The issue of construct validity is another important aspect of instrument design. This instrument clearly has solid discriminating power through the use of well-defined Likert-type scales.

In summary, the reliability and validity of the instrument appear relatively high. The correlations on bogus drug use questions through the test-retest method indicate a high degree of instrument reliability. Instrument validity can be defended in terms of content and criterionrelated validity. Construct validity is demonstrated through the use of welldefined Likert-type scale measures, which give the instrument accurate discriminating power. Convergent validity has not been tested, but can be hypothesized to be high.

Data were analyzed using the MIDAS (Michigan Interactive Data Analysis System) statistical package provided by the Statistical Research Laboratory of the University of Michigan; additional data analysis was done for verification by utilizing an ALGOL program constructed by the technical advisor of the project. Likert-type scales were assigned a 1-5 point scale by the MIDAS computer program, while the categorical variables 
retained their nominal scale values for measurement. Equal interval scales were assumed for the Likert-type scales when calculating the Pearsonian correlation coefficient. Although Likert scales are ordinal, it is acceptable to convert to the interval scale-provided one accepts the limitations of the data interpretation due to scale conversion.

The survey was administered by the junior author, who instructed the students how to answer the questionnaire and remained in the classrooms throughout the administration of the survey.

\section{RESULTS}

The overall item analysis of scores of the total population revealed values reflecting reported substance use varying from light to extremely high use. Table I gives the breakdown by percentages of substance use for the total sample. Of the two drugs reported, alcohol, as expected, showed the highest reported frequency of use. Data were then converted to interval data to determine correlation coefficients. The overall correlates between peer use and personal use ranged from moderately high $(+0.4318)$ to very high $(+0.8021)$. These data produce coefficients of determination values $\left(r^{2}\right)$ of 0.1816 to 0.6434 .

The lowest relationship for the overall population was between quantity of personal use of cigarettes and frequency of peers' cigarette use. The most powerful correlate between the general sample was the relationship between quantity of personal use of alcohol and the quantity of peer use of alcohol. In general, cigarette smoking seemed to produce lower correlations (although they were moderately high) than alcohol use behavior correlates, which were consistently high. Table II shows the total sample correlates.

The data were then analyzed by grade level stratification to obtain a measure of age-specific trends in peer and personal substance use relationships. An item analysis of the responses by age is shown in Table III. Generally, as age increased, so did self-reported frequency and quantity of

Table I. Frequency of Use (Percentage) $(N=181)^{a}$

\begin{tabular}{lrrrrc}
\hline & Never & $\begin{array}{c}\text { Once a } \\
\text { year }\end{array}$ & $\begin{array}{c}4 \text { or } 5 \\
\text { times a year }\end{array}$ & $\begin{array}{c}4 \text { or } 5 \\
\text { times a month }\end{array}$ & $\begin{array}{c}\text { More than } \\
\text { once a week }\end{array}$ \\
\hline $\begin{array}{l}\text { Personal use } \\
\text { Alcohol }\end{array}$ & 31.0 & 23.0 & 23.0 & 15.0 & 8.0 \\
Cigarettes & 79.0 & 6.0 & 6.0 & 2.0 & 6.0 \\
Peer use & & & & & \\
$\quad$ Alcohol & 27.0 & 13.0 & 28.0 & 18.0 & 14.0 \\
Cigarettes & 63.0 & 8.0 & 5.0 & 7.0 & 17.0 \\
\hline
\end{tabular}

${ }^{a}$ Quantity and number of peers who use substances appear in Appendix Table A. 
Table II. Correlates of Peer and Personal Substance Use $(N=181)^{a}$

\begin{tabular}{lccc}
\hline & $\begin{array}{c}\text { Number of peers } \\
\text { who use }\end{array}$ & $\begin{array}{c}\text { Frequency of peers' } \\
\text { use }\end{array}$ & $\begin{array}{c}\text { Quantity of peers' } \\
\text { use }\end{array}$ \\
\hline $\begin{array}{l}\text { Personal alcohol use } \\
\text { Frequency }\end{array}$ & 0.6416 & 0.6413 & 0.7106 \\
Quantity & 0.6072 & 0.5811 & 0.7031 \\
Personal cigarette use & & & \\
$\quad$ Frequency & 0.6575 & 0.4995 & 0.5964 \\
Quantity & 0.5313 & 0.4318 & 0.6323 \\
\hline
\end{tabular}

$a_{p}<0.001$.

substance use. The data were then assigned a metric of $1-5$ for further data analysis.

A common tendency appears as an increase in the strength of the correlation with age in this population, although the seventh-grade students seem to have the highest correlates for certain drug use behaviors. The most significant climb occurs between grades 6 and 7. Table IV displays the correlation differences by grade.

Personal and peer use were then analyzed by sex. Here the results were surprising. The data suggest that for alcohol, sex seems to produce different correlations, especially in one correlation (personal use of alcohol and number of peers who use alcohol). In this case only does the $r^{2}$ value differ by as much as $\mathbf{0 . 2 0}$. Table $\mathrm{V}$ describes the data in percentages. Females had significantly higher correlations than males in all categories of cigarette smoking. Table VI shows these correlations when data are compared by sex.

\section{DISCUSSION}

The correlates between reported personal and peer use were extremely high, especially since 5-point Likert scales were used, which greatly decreases variability compared to wider ranging scales.

The overall trend suggests that nicotine use produces lower correlations between peers' use and personal use than does alcohol. This finding seems to indicate the subjects' perceptions of the degree of risk in certain behaviors in terms of the legal, sociologic, psychologic, and physiologic consequences. It also reflects the intensity of peer support when the youth are involved in certain behaviors.

Evidently, the students do not see cigarette smoking (nicotine use) as being as dangerous as alcohol use. It seems it is not as important to smoke 


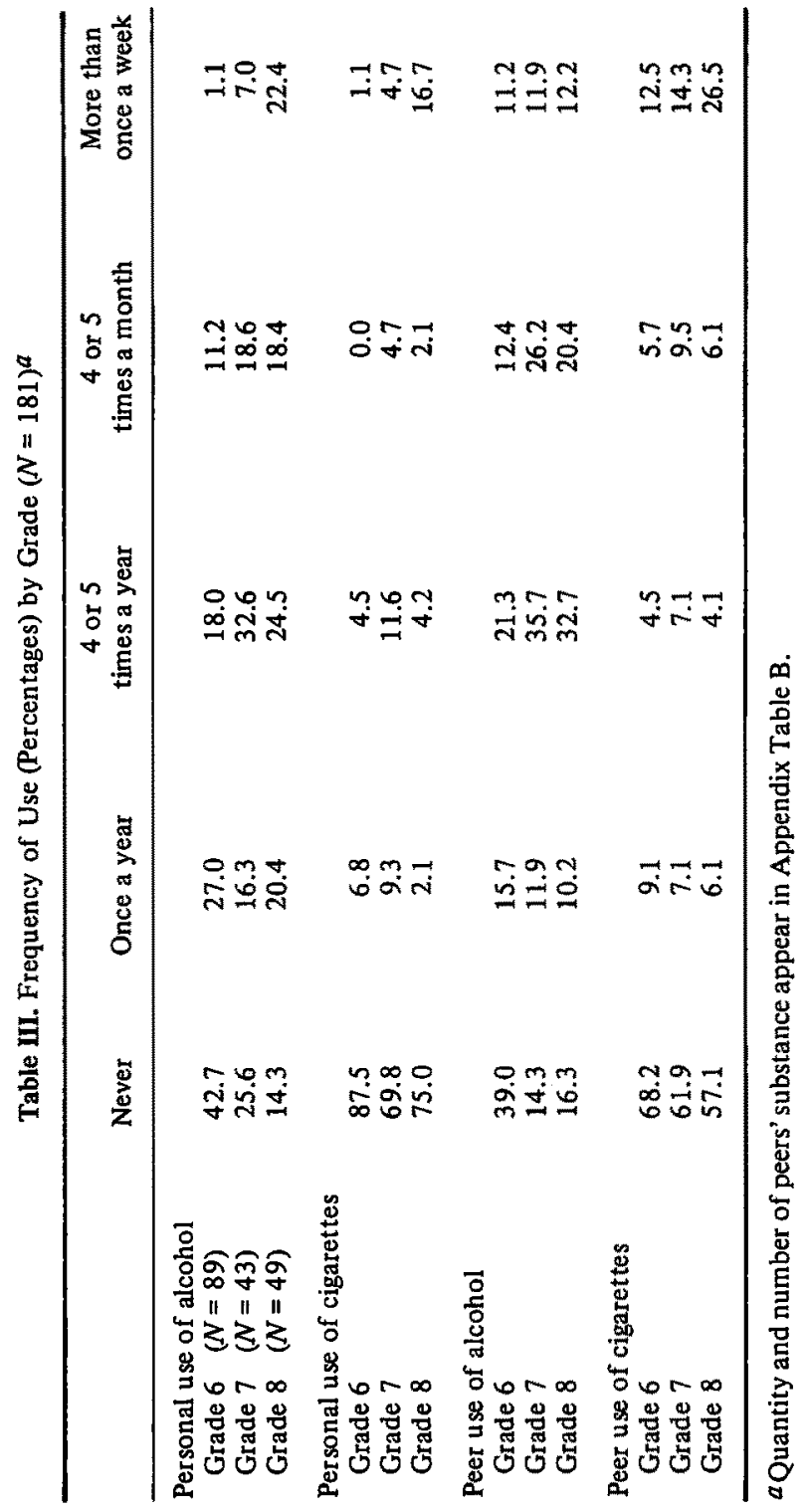


Table IV. Correlates of Peer and Personal Substance Use by Grade $(N=181)$

\begin{tabular}{|c|c|c|c|}
\hline & $\begin{array}{c}\text { Number of peers } \\
\text { who use }\end{array}$ & $\begin{array}{c}\text { Frequency of peers' } \\
\text { use }\end{array}$ & $\begin{array}{c}\text { Quantity of peers' } \\
\text { use }\end{array}$ \\
\hline \multicolumn{4}{|l|}{ Personal alcohol use } \\
\hline Grade $6 \quad(N=89)$ & $0.4274 c$ & $0.4455 c$ & $0.5622 c$ \\
\hline Grade $7 \quad(N=43)$ & $0.7311^{c}$ & $0.7715 c$ & $0.7781^{C}$ \\
\hline Grade $8 \quad(N=49)$ & $0.6185^{c}$ & $0.7119 c$ & $0.7161 c$ \\
\hline \multicolumn{4}{|l|}{ Quantity } \\
\hline Grade 6 & $0.3234 b$ & $0.4620 c$ & $0.6191 c$ \\
\hline Grade 7 & $0.6290 c$ & $0.5632 c$ & $0.6242 c$ \\
\hline Grade 8 & $0.7144^{c} c$ & $0.6389 c$ & $0.7465 c$ \\
\hline \multicolumn{4}{|l|}{ Personal cigarette use } \\
\hline \multicolumn{4}{|l|}{ Frequency } \\
\hline Grade 6 & $0.2820^{b}$ & $0.2326^{a}$ & $0.3230^{b}$ \\
\hline Grade 7 & $0.7671^{c} \mathrm{C}$ & $0.5056 \mathrm{C}$ & $0.6115 c$ \\
\hline Grade 8 & $0.8453^{c}$ & $0.6632 c$ & $0.7208 c$ \\
\hline \multicolumn{4}{|l|}{ Quantity } \\
\hline Grade 6 & 0.0747 & 0.1645 & 0.1368 \\
\hline Grade 7 & $0.6271^{c}$ & $0.4122^{b}$ & $0.5177^{c} c$ \\
\hline Grade 8 & $0.7443 c$ & $0.5898^{c} c$ & $0.8464 c$ \\
\hline
\end{tabular}

$a_{p}<0.05$

$b_{p}<0.01$.

$c_{p}<0.001$.

cigarettes in a peer group that smokes but participation is more likely to be demanded in alcohol-using groups.

Alcohol use shows higher positive correlations when compared to cigarette smoking, suggesting that partaking in drinking behaviors involves more risk and is more dependent upon peer support for the behavior.

The increase with age and the power of the correlations of both substances suggest that peer pressure to use substances increases measurably with age. The correlations increase from moderate (still indicating the presence of peer pressure) to strongly positive, clearly suggesting that students experience more pressure to use substances as they become older. The greater tendency to use substances with friends as age increases seems to reflect an increase in adolescents' desire to engage in perceived adult behaviors as they get older.

Females in the sample report a greater use of cigarettes than do males when their own peer group uses them. These differences might reflect maturity differences between males and females in the early adolescent population, since other studies have shown greater use of cigarettes by younger females. This difference may level off once high school is reached. The male/female differences are significant and suggest that a different dynamic occurs among male and female peer groups. Some 


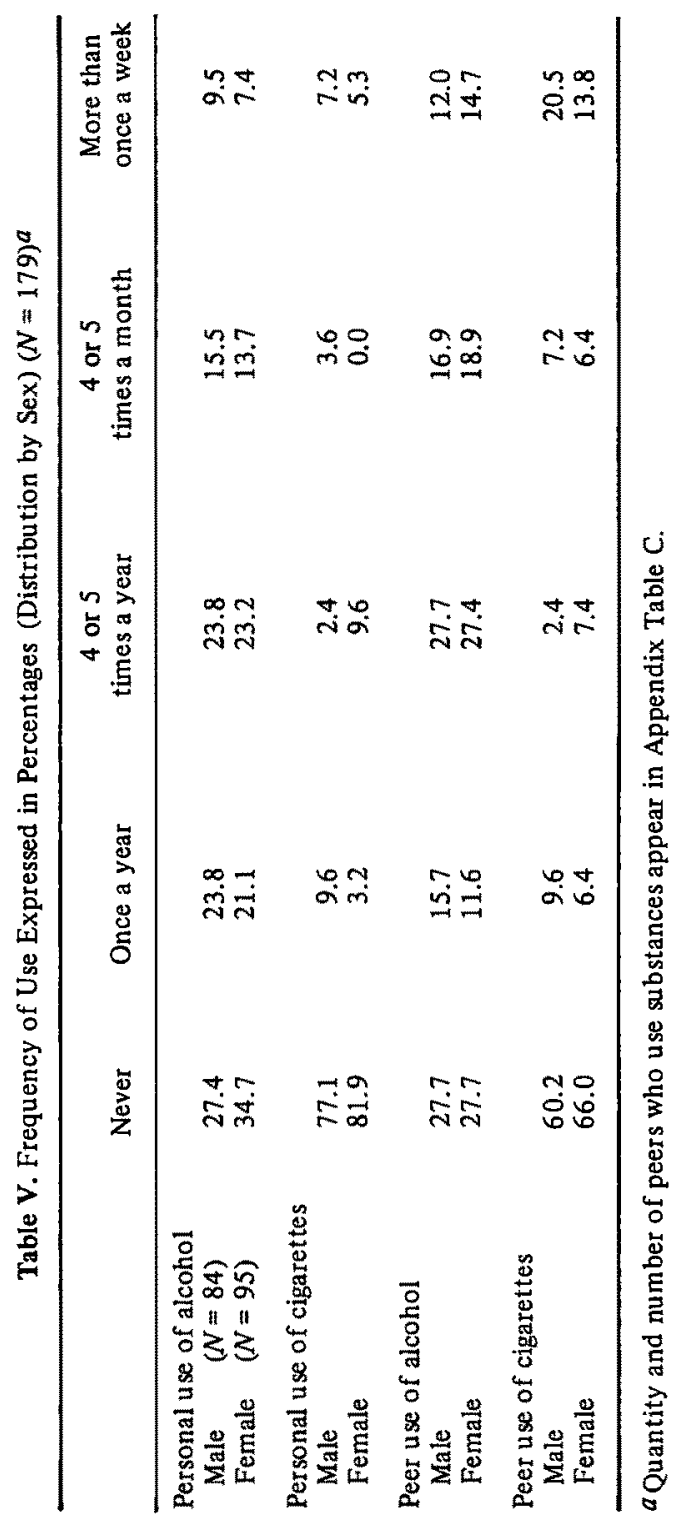


Table VI. Correlates of Peer and Personal Substance Use by Sex $(N=179)$

\begin{tabular}{lccc}
\hline & $\begin{array}{c}\text { Number of peers } \\
\text { who use }\end{array}$ & $\begin{array}{c}\text { Frequency of peers } \\
\text { use }\end{array}$ & $\begin{array}{c}\text { Quantity of peers' } \\
\text { use }\end{array}$ \\
\hline $\begin{array}{l}\text { Personal alcohol use } \\
\text { Frequency }\end{array}$ & & & \\
$\quad$ Male & $0.6838^{b}$ & $0.6311^{b}$ & $0.6766^{b}$ \\
$\quad$ Female & $0.6446^{b}$ & $0.6449 b$ & $0.7443^{b}$ \\
Quantity & $0.6492^{b}$ & $0.6238^{b}$ & $0.7812^{b}$ \\
Male & $0.6581^{b}$ & $0.5332^{b}$ & $0.6394^{b}$ \\
Female & & & \\
Personal cigarette use & $0.6440^{b}$ & $0.4102^{b}$ & $0.5238^{b}$ \\
Frequency & $0.7106^{b}$ & $0.5985^{b}$ & $0.6740^{b}$ \\
Male & & & \\
Female & $0.5180^{b}$ & $0.3551 a$ & $0.5974 b$ \\
Quantity & 0.5881 & $0.5373^{b}$ & $0.6835^{b}$ \\
Male & Female & & \\
\hline
\end{tabular}

$a_{p}<0.01$.

$b_{p}<0.001$.

authorities have suggested that at this age females are less concerned about the health risk than are males.

These data shed light on the powerful relationship between peer use and personal use of alcohol and nicotine among the one-third of American youth who live in rural areas. Variations in correlates between peer and personal substance use seems to be a function of the following factors: (a) the substance being used, (b) the sex of the subject, (c) the age of the subject, (d) the number of friends who use the substance, (e) frequency of friends' use, ( $f$ ) quantity of the substance used by friends.

As is often the case, this study raises as many or more questions than it answers. Additional studies are needed to determine (1) whether these data are specific to the Northern Midwest or apply to rural youth in other regions, (2) whether urban and suburban youth would report similar peer and personal use, (3) whether these trends change in later adolescence and adulthood, (4) how these data compare to peer and personal practices with other illicit substance use.

\section{ACKNOWLEDGMENTS}

Thanks are due to Paul J. Olson, Systems Software Manager of Wormald U.S., Inc., who served as technical advisor to the project, and to Robert Dedrick, of the University of Michigan, for his valuable statistical advice. We also wish to thank anonymous reviewers for their helpful comments on an earlier draft of this article. 


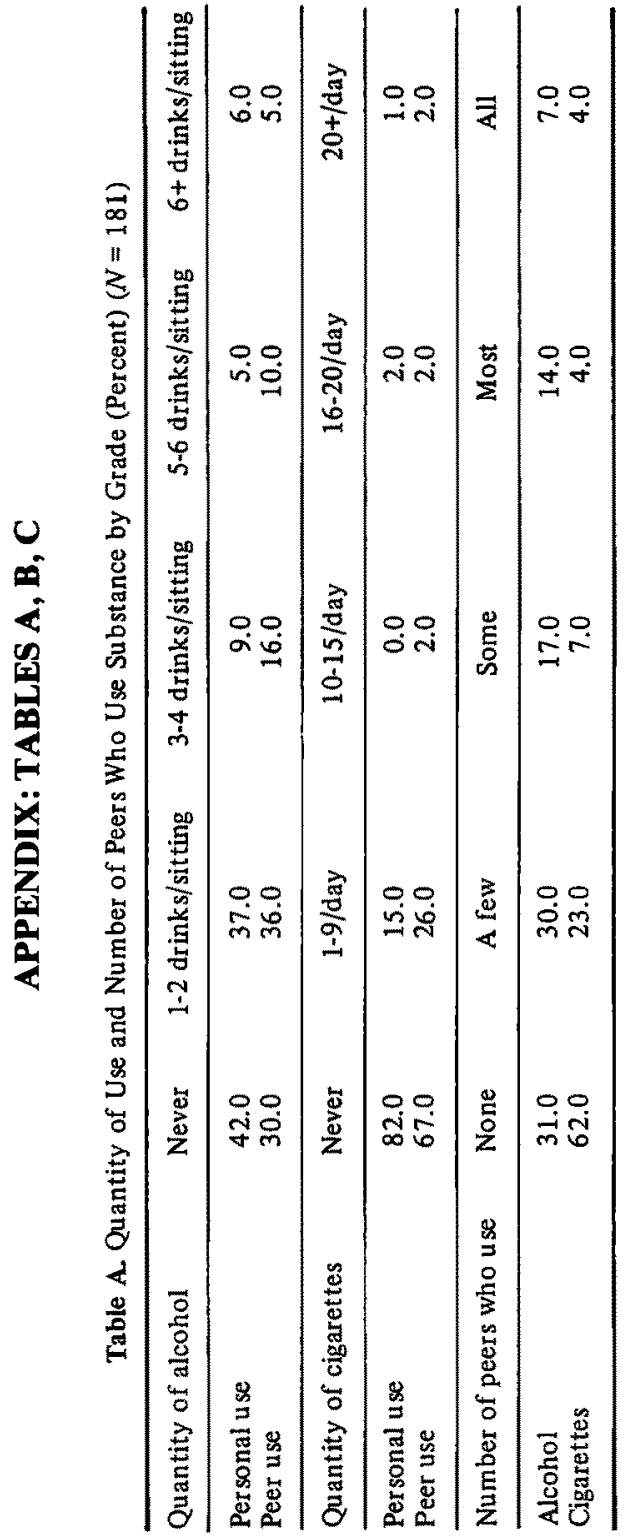




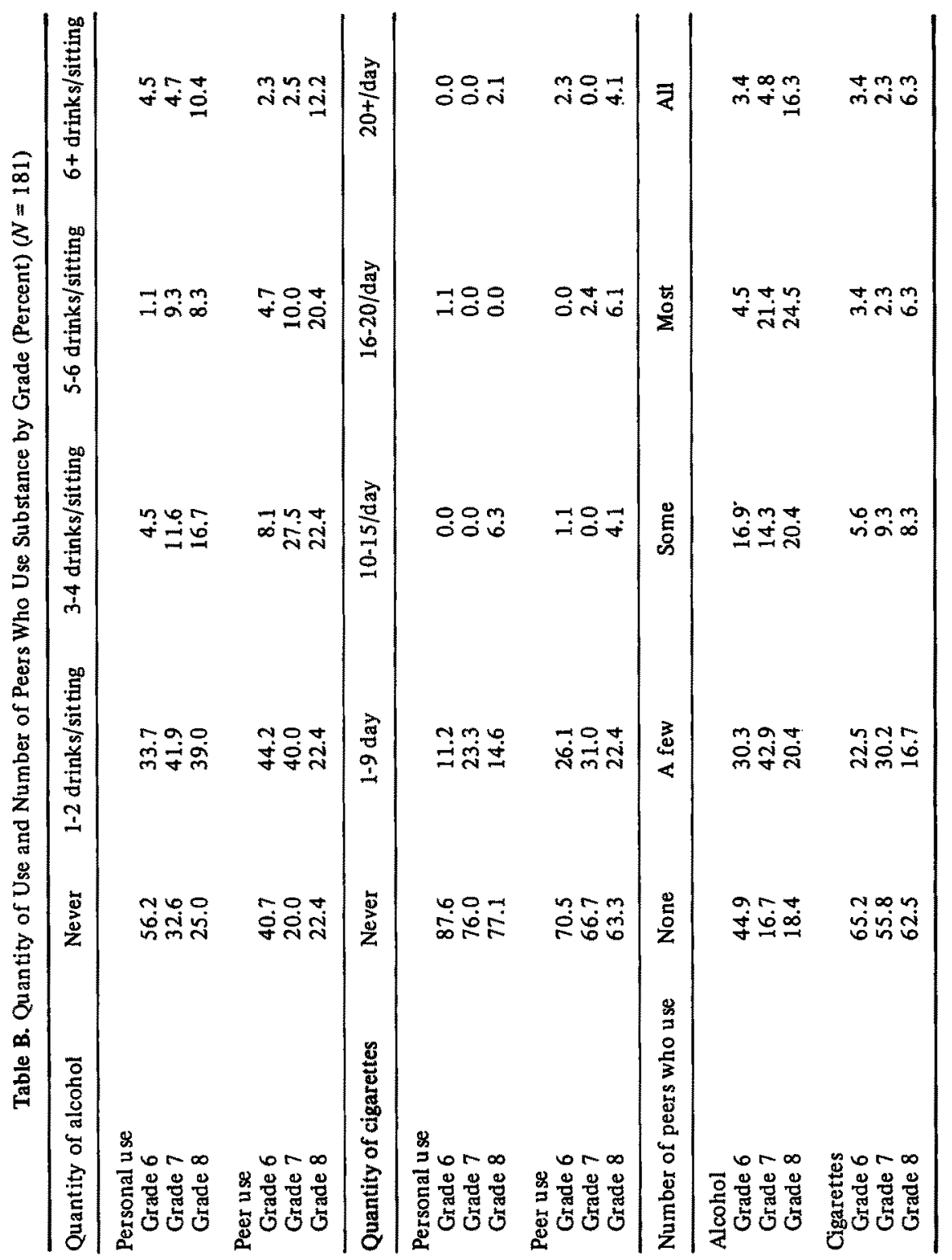




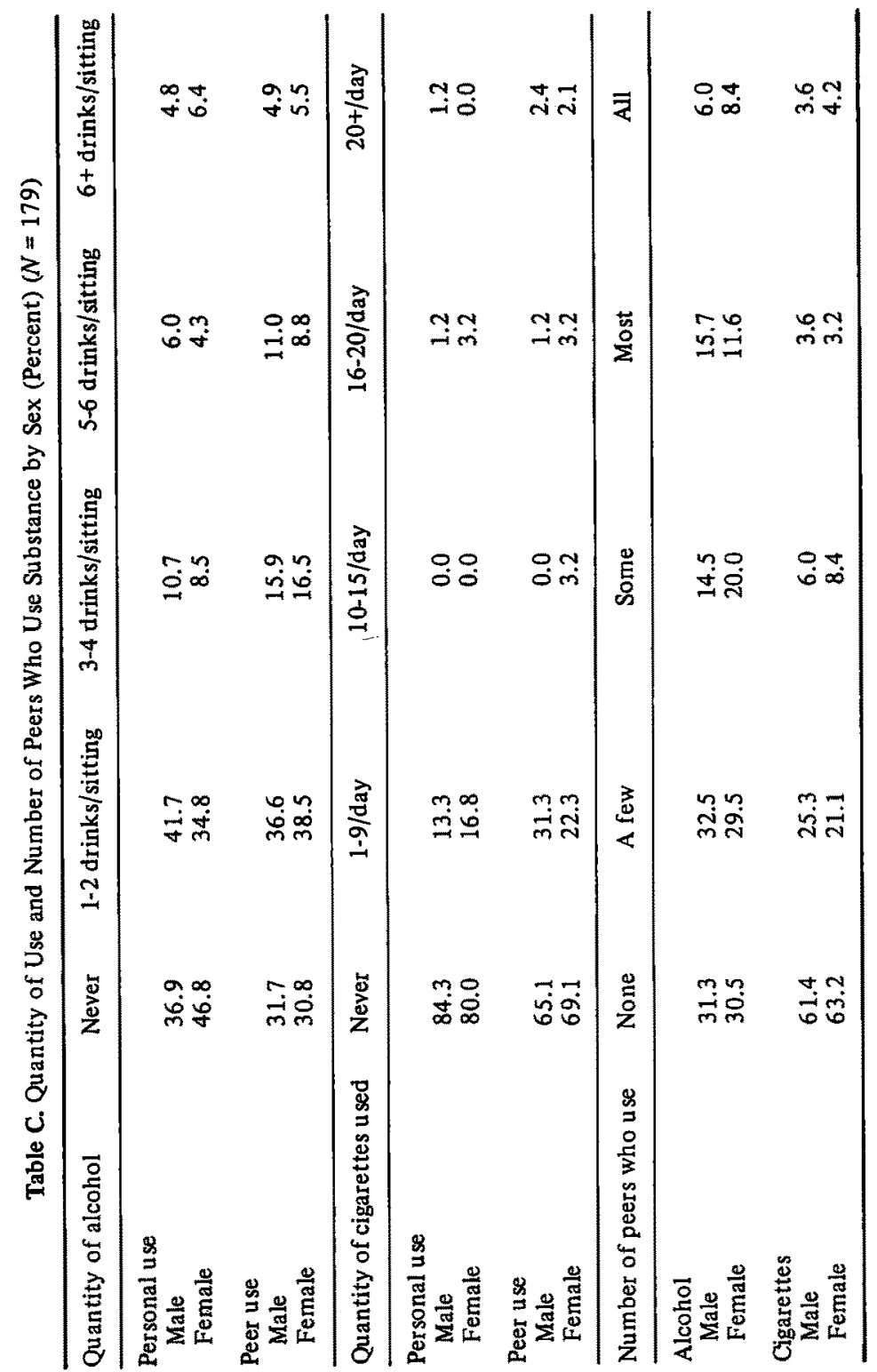




\section{REFERENCES}

Andrews, K. H., and Kandel, D. B. (1979). Attitude and behavior: A specification of the contingent consistency hypothesis. Am. Social Rev. 44: 298-310.

Huba, G. J., and Bentler, P. M. (1980). The role of peer and adult models for drug taking at different stages in adolescence. J. Youth Adoles. 9:449-465.

Jessor, R., and Jessor, S. L. (1977). Problem Behavior and Psychosocial Development, Academic Press, New York.

Kerlinger, F. N. (1973). Foundations of Behavioral Research, Holt, New York.

Levine, E. M., and Kozak, C. (1979). Drug and alcohol use, delinquency, and vandalism among upper middle class pre- and post-adolescents. J. Youth Adoles. 8: 91-101.

Michigan Employment Security Commission. (1982). Research and Statistics. Labor Market Analyst Section.

Napier, T. L., Carter, T. J., and Pratt, M. C. (1981). Correlates of alcohol and marijuana use among high school students. Rur. Sociol. 46(2): 319-332.

Sarvela, P. D., and McClendon, E. J. (1983). Early adolescent substance use/abuse in rural northern Michigan. Catalyst 2(1): 62-67.

Stephens, R. C. (1980). The hard drug scene. In Scarpitti, F. R., and Datesman, S. K. (eds.), Drugs and the Youth Culture, Sage, Beverly Hills, Calif.

Tolone, W. L., and Dermott, D. (1975). Some correlates of drug use among high school youth in a rural midwestern community. Int. J. Addict. 10(5): 761-777. 